\title{
Can Addax and Oryx be saved in the Sahel?
}

\author{
John Newby
}

Very few reserves exist to protect the arid-lands fauna of West Africa, particularly in the sub-desert zone, and the large mammals, such as addax, scimitar-horned oryx and dama gazelle are disappearing. New reserves are planned but they could be too late. Many permanent waterholes have been dug, and the nomads (and their livestock) tend to stay near them, depriving the wild animals of their traditional dry-season haunts. Firearms have made hunting easier, and the slow-running desert animals cannot compete with motor vehicles -.many die of heat exhaustion, calves are abandoned in the chase and unborn young aborted. Rational utilisation of wildlife could be of immense benefit to the people, but protection is the first priority. To achieve this FPS and PTES have launched an appeal for the scimitarhorned oryx.

Arid lands have few large mammal species, but in the past these few have had huge populations. Today in West Africa the larger mammals of the desert, sub-desert and sahelian zones are rapidly disappearing, and there are very few reserves to protect the survivors. The highly endangered scimitar-horned oryx and the addax typically inhabit the sub-desert lands - the transition zones between true desert (Sahara) and the Sahel, with a rainfall of under $200 \mathrm{~mm}-$ and only one reserve exists to protect this sahelo-saharan fauna, the Ouadi Rimé-Ouadi Achim Reserve in Chad.

Sahel is an Arabic word meaning 'shore', referring here to the sparsely vegetated fringe of the saharan sand-seas. But today the Sahel is generally defined as the band of land south of the Sahara where the annual rainfall is $150-550 \mathrm{~mm}$; the true desert, the Sahara, has under $50 \mathrm{~mm}$.

Several countries, including Mali, are planning new desert or sub-desert reserves, although usually the characteristic fauna has either vanished or is rapidly doing so, and to save anything at all will require strong protection measures by both governments and international bodies. But once given full protection all these well-adapted mammals of the arid lands could build up their populations again. All are capable of going without drinking water for 9-10 months of the year, addax probably longer, and most of them make annual or seasonal migrations in response to the climatic fluctuations.

Addax Addax nasomaculatus, slender-horned gazelle Gazella leptoceros, and the Barbary sheep Ammotragus lervia are the most desert-loving species, all highly adapted to eking out their existence on the open regs (sterile pebbly plains) and ergs (sand seas) of the Sahara, or, in the case of the Barbary sheep, in and around the rocky desert massifs. Because their environment and behaviour are such very good defences against outside interference, the future for them looks more secure than it does for the species of the sub-desert lands.

The scimitar-horned oryx Oryx dammah is the mammal par excellence of the sub-desert, and by far the most endangered. Animals of rolling dunes, grassy steppes and wooded inter-dunal depressions, scimitar-horned oryx very rarely penetrate either true desert or true sahel country. But only in Chad do they occur in any numbers; there is a small group in Niger, and perhaps a few dozen 
An exhausted oryx

in Mali and Sudan. The total world population can hardly exceed 2000. The dama gazelle Gazella dama, another member of the sahelo-saharan fauna, grazes the same sort of pastures as the oryx but maintains its ecological divergence through its browsing habits; the dorcas gazelle Gazella dorcas, the most ubiquitous, is the least in danger. Cheetah Acinonyx jubatus and ostrich Struthio camelus are rare and need protection, but the smaller omnivores and the carnivores are not in immediate danger; indeed some, such as the fennec fox Fennecus zerda and the zorilla Ictonyx striatus, are expanding their ranges as a result of widespread desertification.

The causes for the overall decline of the sahelo-saharan fauna are not difficult to see.

\section{The Spreading Desert}

The reasons for the increasing aridity and desertification in West Africa are both natural and artificial. Since the Neolithic Age the climate of the Sahara and sub-sahara has become naturally drier; rainfall appears to have diminished to about half that enjoyed during the 'climatic optimum' of some 5-6000 years ago. Neolithic graffiti clearly show the present-day sudano-sahelian fauna in areas which are now desert: elephants, giraffes, hippopotamus and antelopes are all pictured in paintings and engravings. Wetter and drier periods have occurred, but, because they were relatively short, have gone undocumented until the historic era, and, more pertinently to the study of West Africa, until Arab and European explorers crossed the continent and reported their findings. Certainly the sahelo-saharan animals living at the extreme of the Inter-Tropical Front, have always known climatic and environmental fluctuations, and have evolved their migratory behaviour in response to these. Nevertheless, drought does have serious biological effects, and scimitarhorned oryx will even abandon new-born calves in times of drought. The weakening effects may also make the ungulates.more prone to disease.

But the worst effects come when drought is combined with hunting, for the animals' weakened state then makes them both easier to hunt and much more susceptible to heat exhaustion, and may lead to them abandoning their calves or aborting unborn young. Moreover, they may migrate into areas of human 


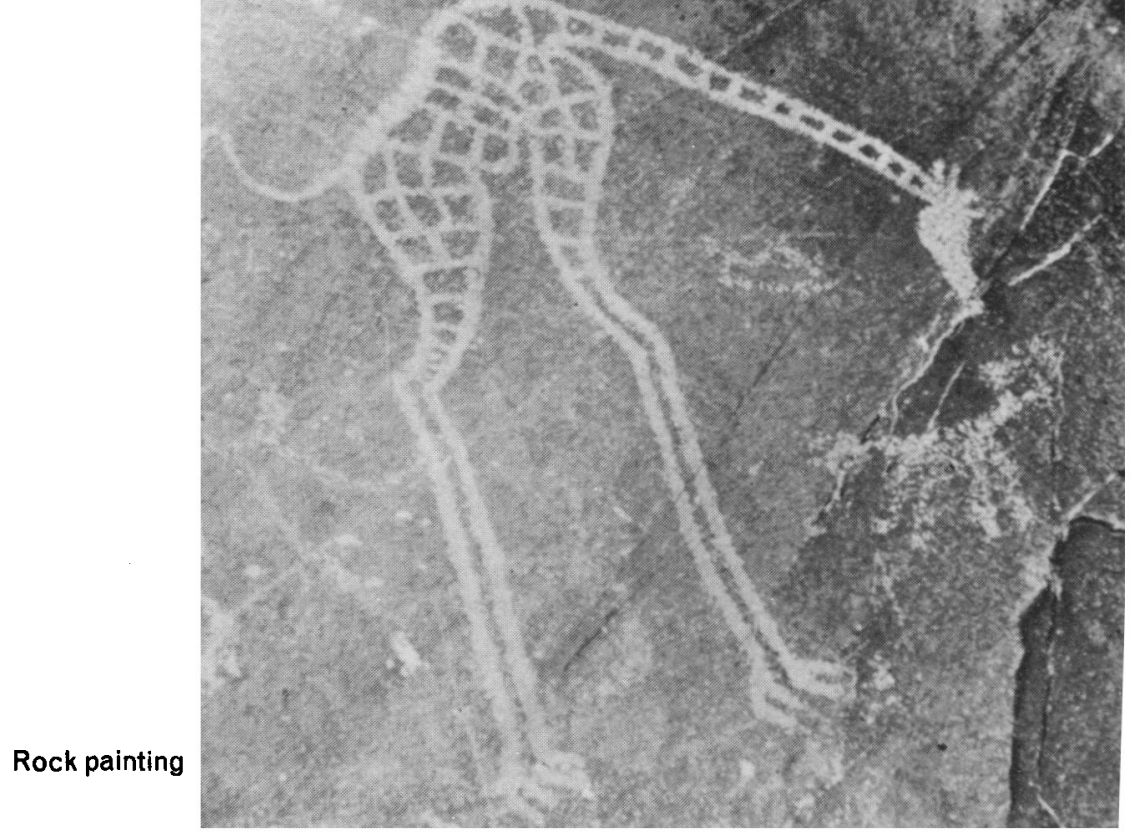

settlement where they are kept out of the best pastures, and forced to graze poor or marginal areas, or, more often, ruthlessly slaughtered by large-scale hunting expeditions. During 1972-73, hunters came great distances to profit from the mass exodus of oryx and dama gazelles from Chad's drought-stricken Ouadi Rimé-Ouadi Achim Faunal Reserve.

At the same time desertification brought about by man is seriously affecting the wildlife. Overgrazing leads to desert encroachment and the loss of large tracts of rich pastures. Equally serious is the destruction of tree cover, both on the dunes and in and around temporary pools and watercourses. Shade is important for all the wildlife; ungulates especially spend many daylight hours in shade to conserve water. The felling of natural wind barriers along wadis is also having drastic effects by allowing tongues of sand to invade and cut the watercourses.

\section{Poaching and Hunting}

Hunting is undoubtedly the greatest single cause of the sahelo-saharan fauna's rapid decline. Wildlife has always played an important role in the lives of arid-land people, and neolithic hunting scenes are common in the Saharan massifs of the Air, Fezzan, Hoggar and Tibesti. Until this century whole populations lived from and by the hunt, and today most nomadic peoples exploit their wildlife whenever possible. The introduction of firearms was the turning point for many species, although desert and sub-desert terrain does not necessarily favour such weapons, which in the early days were more effective on savannas and in forests where stalking was possible. But motorised transport opened up the waterless deserts, and the slow-running animals were no match for the motor car. Whole herds were wiped out, and many animals left to die of heat exhaustion following the chase.

After the Second World War motor vehicles became commonplace with the mineral and petro-chemical exploitation of the Sahara, and expatriate mining, mineral and administrative personnel started a slaughter that has carried on into post-independence Africa. At the same time I cannot accept that 


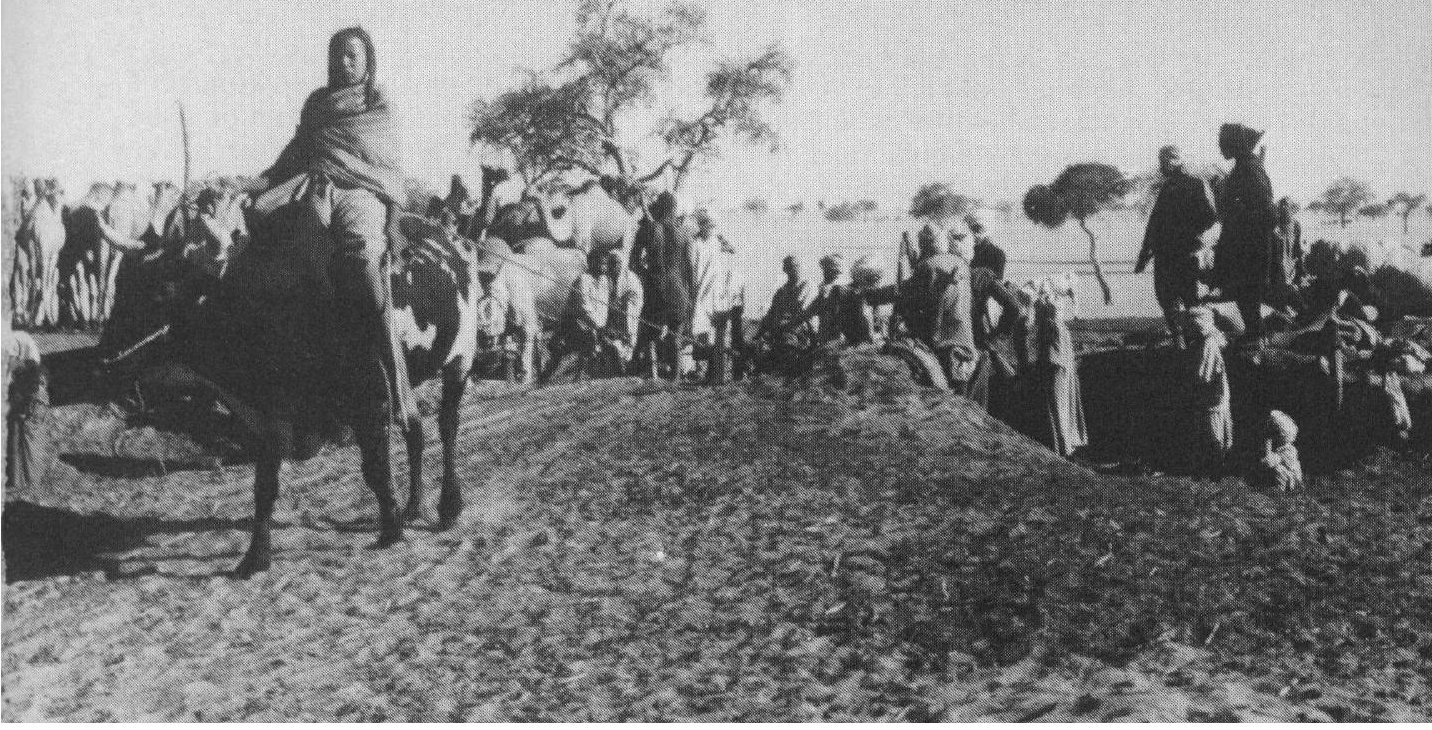

At the well

traditional hunting methods are not doing damage today. If modern methods had not threatened the survival of so many species, traditional hunting would obviously have much less effect; but now that they are depleted the sooner all forms of irrational hunting stops, the quicker they will be able to recover. In a country like Chad, which has few presently exploitable mineral or petro-chemical resources, vehicles and firearms have had less impact. But the nomads' life has changed too: thirty years ago a horse was a real luxury; today virtually every nomad family possesses at least one, increasing both the amount of hunting and its effectiveness.

\section{Bad Development?}

Exploitation of pastoral wealth is certainly one answer to the development problems of countries like Chad, Mali and Niger, and they must be free to exploit their limited natural resources to the full, but is it in their own interest to exploit some to the detriment of others? For it is being done now with little care or respect for the environment, or, indeed, with the foresight needed to make the most of the resources, and wildlife, which is part of the resources, is being sacrificed. Pastoral development involves water resources. Sahelosaharan pastures are rich and productive but also extremely delicate if not treated carefully, and they can be irreversibly changed and degraded. Already vast tracts of land around the well-sites are becoming barren or infested with unnutritive plants.

Within the last fifteen years, many new permanent-water boreholes have been dug in areas which, although waterless, have rich pastures. Traditionally oryx, addax and dama gazelle used these in the hot season when they need the most nutritive pasture to supply both food and water, but the presence of nomads round the wells keeps them away. Moreover, this reckless policy of wholesale well-digging may well prove to be self-destructive, as could easily have been predicted from the erratic climatic conditions. The nomads have become more or less sedentary around their new water points, but it is always 
unpredictable from year to year whether there will be pasture in any one area, and a sahelo-saharan wet season usually results in a patchy mosaic of good, poor and non-existent pasture. In the recent drought in West Africa cattle were dying in their thousands for lack of pasture, not water.

Wildlife has an important role to play in the development of the sahelian nations, and involves rational utilisation as well as protection and preservation. But the present sorry state of the arid-lands fauna means that the protection aspects must be stressed before any sort of rational exploitation can be considered feasible.

New national parks and game reserves are essential if the sahelo-saharan fauna is to be saved, and before they can be established there must be comprehensive research. Much information about the wildlife's requirements can be got from the nomads themselves. Strong legislation will be needed, and law enforcement ensured in each case by an adequate force of rangers. Management must draw on experience in the only effective sahelo-saharan reserve, the Ouadi-Rimé Achim in Chad.

Such measures would allow the species to recover their numbers and demonstrate their remarkable productivity. For, being virtually predator free and, on the whole, epidemic free, the sahelo-saharan ungulates are very productive. Observations made in Chad show that species like the scimitar-horned oryx have an annual birth-rate of something like 12-15 per cent of the total population, and recruitment after juvenile mortality may be as high as 10-14 per cent annually. Between 1973 and 1976, the number of oryx in the Ouadi-Rimé reserve increased from an estimated 2500 to 3500 head, due to a series of good wet seasons combined with a ruthless and efficient control of poaching. Even so, poachers probably killed up to 250 oryx a year undetected.

To provide the arid-lands fauna with the sort of protection it requires is expensive and, since the sahelian nations are some of Africa's poorest, much will depend on international aid. Treating the wildlife as an economically exploitable resource would solve many national economic problems and is the only way to save it. Wildlife must take its place alongside pastoralism, agriculture and mining in a multi-role resource development plan for the sahel. Tourism, sport-hunting, cropping for meat and hides could all be realistic economic roles for wildlife in West Africa, as they are in East and South Africa, once the herds have been allowed to build up again.

John Newby, Gledmar, Caistor Road, Market Rasen, Lincs LN8 3JA.

John Newby has been working in Chad and Niger since 1971 on the protection and conservation of the wildlife of the arid lands. In 1974 he was the first to alert conservationists to the effects on wildlife of digging permanent waterholes for the nomads' livestock. In 1976 the FPS $100 \%$ Fund made him a grant to support his anti-poaching work in the Sahel.

\section{To the Rescue of the Tamaraw}

In July 1979 President Marcos of the Philippines appointed a small Presidential Committee for the Conservation of the Tamaraw vith initial funds and wide powers to initiate projects and appoint technical and scientific assistance, including overseas help. Tony Parkinson, who worked for many years in Kenya, has been appointed Consultant to the Ministry of Natural Resources and seconded to the Presidential Committee. 